\title{
РЕЗЮМЕ ИССЛЕДОВАНИЯ ТУРИЗМА КИТАЯ
}

\section{SUMMARY OF CHINA TOURISM RESEARCH}

Liu Ying

Summary: The article discusses the origin and semantic meaning of the concept of "tourism" in China, as well as the views of Chinese scientists on this phenomenon, as well as some specific features of ideas about the essence of the concept of "tourism" in China, which have been forming over many centuries. There is an old Chinese saying: «Read thousands of books and travel thousands of miles.» China has an ancient culture and rich tourism resources, attracts a large number of domestic and foreign tourists, which contributes to the rapid development of the tourism industry. With the gradual increase in tourist consumption, the desire of tourists for the quality of tourism services is growing. With the rapid development of tourism in China, tourism research is especially important.

Keywords: China, Tourism, Definition, Types of tourism in China, Tourism functions.

\author{
Лю Ин \\ Аспирант, Дальневосточный федеральный \\ университет (2. Владивосток) \\ liuying_sw@mail.ru
}

Аннотация: В статье рассматривается вопрос о происхождении и смысловом значении понятия «туризм» в Китае, а также о взглядах китайских ученых на этот феномен, а также некоторые специфические особенности представлений о сущности понятия «туризм» в Китае, формирующиеся на протяжении многих веков. Существует старая китайская поговорка: «Читай тысячи книг и путешествуй за тысячи миль». Китай имеет древнюю культуру и богатые туристические ресурсы, привлекает большое количество отечественных и иностранных туристов, что способствует быстрому развитию туристической индустрии. С постепенным увеличением туристического потребления, растет стремление туристов к качеству туристических услуг. В связи с быстрым развитием туризма в Китае исследования в области туризма особенно важны.

Ключевые слова: Китай, туризм, определение, виды туризма Китая, функции туризма.

«источник пути»[2]. Пятьдесят шестая триграмма - это туристическая триграмма, обозначающая путешествие, перемещение. Это представление о туризме отражает обобщение опыта понимания туристических явлений до династии Чжоу. Обратим внимание на то, что тесно связанные с туризмом понятия «тур» и «путешествие» до периода Цао Вэй Трех Королевств использовались отдельно. Со времен Цао Чжи (192-232) китайцы стали использовать понятие «туризм» для обозначения как исследовательских путешествий, так и развлекательного туризма [3].

В период правления императора Тайцзуна ученый Конг Инда (574-648) определил понятие «путешествовать» следующим образом: «Путешественник означает гость, путник. Он теряет место жительства и отправляется в путь». Определение Конга Инды о «госте во время путешествия» описывается в аспектах: «быть в дороге» и «быть в других местах, где вы не живете» [4]. Краткое определение Конг Инда (574-648) содержит следующие три значения: Туризм является синонимом подвижной жизни человека, то есть наименованием человека как живущего в движении. Туризм - это общий термин для мобильной жизни, которая происходит вне человека, включая материальную и духовную жизнь. Туризм - это общий термин для обозначения ряда видов деятельности, которые находятся вдали от привычных мест жительства. 


\section{Первая группа. Туризм как социально-экономический феномен}

Профессор Чжан Линюнь (张凌云Lingfalls, 1984) отметил, что туризм - это недолгий образ жизни, изменение условий жизни и работы. «Туризм и природные потребности связаны с поведением человека». Сумма социальных отношений и явлений, порождаемых удовлетворением и освобождением. Сам туризм имеет много атрибутов, таких как экономические, культурные и социальные атрибуты [5]. Определение туризма от Ван Юхая (王玉海) подразделяется на два смысла, узкий и широкий. Он считает, что узком смысле определение туризма таково: туризм - это опыт досуга людей в нестандартных условиях. Это недолгий образ жизни и живое состояние. В широком смысле: туризм - это поездки людей за пределы места работы, для миграции или отдыха за пределами сообщества, в котором они живут и работают. [6].

Бао Цзиган и Чу Ифан (保继刚, 楚义芳) считают, что туризм «является социальным и экономическим явлением, возникающим в определенных социальных и экономических условиях. Он является частью рекреационной деятельности. Это человеческий опыт, социальное поведение, индустрия, а также географическое явление» [7]. Гао Кун (高璟), Ву Биху (吴必虎) и Ли Мими ( 李咪咪) считают, что туристическая деятельность не может уйти от неотъемлемого атрибута «отрешенности», который отражает своего рода отношения между человеком и землей. Нахождение вне привычного места для отдыха является наиболее важным атрибутом туризма [8]. Гао Су (高苏) предположил, что туризм является одним из способов отдыха [9]. Чжан Байпин (张白平) и Пэн Ин (彭瑛) считают, что туризм является формой отдыха, а отдых и работа являются двумя основными видами деятельности людей, и поэтому каждый день людей делится на рабочее время и свободное время, воспроизводясь снова и снова [10].

Таким образом, туризм является экономическим явлением, вызванным деятельностью человека. Это сумма социальных отношений и явлений, при которых люди покинули свою обычную среду обитания и провели ряд выездных мероприятий.

\section{Вторая группа. Туризм как феномен культуры и философии}

Некоторые известные ученые в современном Китае определяют туризм в культурологическом плане следующим образом: Фан Нэнци (范能船) считает, что туризм - это широкая культурная деятельность, которая является не только процессом культурного творчества, но и процессом потребления культуры. История туризма соответствует истории человечества. Профессор Цао
Шиту (曹诗图) считает, что туризм - это различные виды физической и психической свободы, такие как путешествия, осмотр достопримечательностей и пребывание вне среды, в которой люди часто живут и работают, с основной целью отдыха, получения эстетических впечатлений и знаний. Суть туризма - «бесплатный физический и умственный опыт в разных местах» [11]. С точки зрения изучения человека и теории систем Ма Яофэн (马耀峰) и другие считают, что сущность туризма - это сознательная деятельность или опыт самосовершенствования и развития людей с целью достижения физического и умственного удовольствия [12].

Таким образом, в культурологическом контексте считается, что суть путешествия - это культурное познание и свободный физический и умственный опыт в разных местах.

\section{Третья группа - комплексное определение}

Профессор Се Яньцзюнь (谢彦君) в книге «Базовый туризм» описал текущие тенденции «обобщения» и «утилитаризма» в определении туризма. Он требует некоторого опыта в социальных, развлекательных и потребительских атрибутах в сфере развлечений» [13]. Чжэн Юфэй и Хуан Жун (郑宇飞, 黄蓉) проанализировали с теоретической точки зрения философию туризма, сказав, что «туризм является основной целью людей, путешествующих и находящихся вне повседневной жизненной среды с основной целью удовольствия, эстетики и других духовных удовольствий. Туризм включает людей, краткосрочный отдых за пределами места пребывания и межкультурную коммуникацию» [14]. Ву Биху (吴必 虎) считает, что путешествия существуют во множестве возможностей, во многих дисциплинах и во многих областях. Считается, что путешествие - это не просто узкое «удовольствие» после общих поездок, деловых поездок, отдыха, потребления путешественниками. [15]

\section{Вимы туризма в Китае}

Специфика туризма в Китае отражается также в выделении его видов. Существует много классификаций китайских видов туризма. Например, согласно Су Айцзюнь «О взаимоотношениях между международным туризмом и внутренним туризмом и обсуждении с товарищем Чжан Цзянем» туризм в целом можно разделить на внутренний туризм и международный туризм по географическому охвату. Согласно исследованиям Лю Хайлонга, Чжан Ю и других, посвященным различным аспектам туризма, виды туризма можно обобщить в соответствии с классификацией целей туризма, которые можно разделить на культурный туризм, спортивный туризм, экотуризм, развлекательный и рекреационный туризм, деловой туризм, медицинский туризм и так далее [16]. 
Итак, туризм может быть разделен на следующие типы по географическому охвату: 1. Международный туризм: турист - лицо, покинувшее страну своего проживания и посетившее другую страну продолжительностью более 24 часов. 2. Внутренний туризм относится к туризму, при котором жители страны покидают свои места жительства и отправляются в другое место в стране. [16]. По режиму передвижения туризм можно разделить на следующие типы: 1. Групповые поездки - это коллективный способ путешествия, основным организатором которого является туристическое агентство. 2. Индивидуальные поездки, также известные как поездки самостоятельно и с помощью участников [17].

По цели туризма его можно разделить на следующие виды: 1. Культурный туризм. В процессе исследования туризма очень важным содержанием исследований является культура туризма, которая также является основной ценностью антропологии туризма. Определение культурного туризма относится к поведенческому процессу осознания цели восприятия, понимания и наблюдения за конкретным содержанием человеческой культуры посредством туризма [18]. 2. Спортивный туризм: туризм с основной целью спорта. Туристы участвуют в туристических проектах, укрепляя физическое здоровье и выполняя физические упражнения. Это могут быть экстремальные путешествия, альпинизм, автопробег и т. д. [19]. 3. Экотуризм. Термин «экотуризм» был впервые предложен Всемирным союзом охраны природы (МСОП) в 1983 году. В 1993 году Международная ассоциация экотуризма определила его как туризм с двойной ответственностью за защиту окружающей среды и поддержание жизни местного населения в процессе осуществления туристической деятельности. Участники должны иметь сильное экологическое восприятие и осознание своей деятельности. 4. Осмотр достопримечательностей. Посредством осмотра достопримечательностей туристы могут изменить среду обитания, расширить кругозор, расширить свои знания, развивать свой темперамент и чувствовать себя счастливыми, ценить красоту природы, наслаждаться вкусом современной городской жизни и удовлетворять потребности шоппинга в других местах [20]. 5. Рекреационный туризм. Рекреационный туризм относится к туристической деятельности, основной мотивацией которой является отдых [21]. 6. Деловой туризм относится к туризму с основной целью ведения определенного бизнеса, и это туристическое поведение, возникающее в процессе путешествия. [22]. Медицинский туризм. Медицинский туризм является одной из форм туризма, которая сочетает в себе туризм и медицинские услуги [23].

В Китае существует множество классификаций туризма. У ученых есть свои взгляды. Приведенные выше классификации встречаются чаще всего. В будущем китайские ученые разработают более систематическую классификацию туризма.

\section{Функшии туризма}

Туризм - это особая отрасль, которая предоставляет туристические услуги туристам на основе туристических ресурсов, видов деятельности. Туризм - это комплексная деятельность, объединяющая красоту природы, общества и искусства, которая помогает раскрывать отношения между людьми и природой, а также между людьми [24]. Функции туризма в Китае во многом совпадают с общемировыми тенденциями, но также имеют специфику. Экономическая функция. Будучи комплексной отраслью, туризм способствует решению проблемы занятости в Китае, содействию развитию других отраслей, развитию региональной экономики и ускорению строительства инфраструктуры в туристических направлениях, что в конечном счете ведет к улучшению жизни местных жителей.

Оздоровительная функция. В современном обществе, с ускорением темпов жизни и работы, люди перегружены работой, жизнью и социальными отношениями в течение длительного времени [25]. Если взять в качестве примера культурное здоровье Китая, то основными идеями являются здоровье традиционной китайской медицины, здоровье даосизма, китайская чайная культура и культура тайцзи. Основными средствами здравоохранения в сочетании со строительством мест для оздоровительного туризма, в конечном итоге, станет достижение полного спектра услуг по уходу за телом и разумом, а также интеграция природы и человека. Это уникальная точка оздоровительного туризма Китая.

Функция межкультурной коммуникации. В туризме разные культуры могут общаться и сливаться. Говоря иносказательно, искры мудрости сталкиваются при обмене, и сущность разных культур извлекается в результате слияния. По словам Марииновского, «Культура это набор инструментов и набор обычаев - привычек человеческого тела или разума, которые прямо или косвенно удовлетворяют потребности человека [26]. Фактически культура - это процесс сублимации, который отвечает потребностям человека и должен удовлетворять потребности стимулирования развития и постоянного создания ценности».

Функция связи. Упомянутая здесь коммуникационная функция может быть широко понята как неформальное не модерируемое общение. Особенности этого общения всеобъемлющие, длительные и всесторонние. Например, эмоциональное общение между друзьями, родственниками и близкими [27]. Сочиальная функция. Туризм известен как индустрия, свободная от табачного дыма, что указывает на то, что индустрия туризма является отраслью с относительно небольшими экологиче- 
скими затратами и относительно высоким уровнем смягчения последствий. Туризм - причина существования людей и социальной культуры. Туризм - это не только индустрия, но и важная часть «мягкой силы» страны (культурного обаяния) [28].

Учебная, познавательная функция. Первыми людьми, которые путешествовали, были знающие люди. Они любовались пейзажами и восхищались древними памятниками [29]. Образовательная функция туризма - это влияние и роль туристической деятельности в улучшении знаний, навыков, физического здоровья людей и формирования или изменении сознания людей.

Таким образом, с непрерывным укреплением экономической мощи Китая туризм стал неотъемлемой частью жизни людей сегодня. Есть много соответствующих записей. Укрепление культуры туризма играет жизненно важную роль в развитии экономики туризма. «Туризм это экономическая культурная деятельность и экономическая деятельность, имеющая большое культурное значение». в настоящее время в Китае понятие «туризм» включает в себя экономические, культурные, социальные и др. аспекты. Туризм - это вид физического и психического опыта, при котором люди путешествуют и остаются в местах вне повседневной жизненной среды с основной целью развлекательных, эстетических и других духовных удовольствий. Это краткосрочная жизнедеятельность в свободное время и межкультурная коммуникационная деятельность. Это также социальноэкономический феномен, возникающий в определенных социальных и экономических условиях, который является частью рекреационной деятельности, социального поведения, промышленности, совокупности социальных отношений и явлений, порождаемых удовлетворением и освобождением, а также является своего рода географической переменой места пребывания.

Китайский туризм все еще находится в стадии развития, и есть много других функций, которые необходимо развивать. С развитием индустрии туризма китайский туризм будет развиваться все более и более совершенным.

\section{ЛИТЕРАТУРА}

1. Редактор редакции словаря Института лингвистики Китайской академии общественных наук. Главный редактор Вэй Цзянгун. Словарь Синьхуа // Издано издательством Beijing Commercial Press. 11-е издание. -2011, -322c. 中国社会科学院语言研究所词典编辑室编辑. 主编魏建功. 新 华字典// 北京商务印书馆出版. 第11版. 2011年.322页.

2. Тянь Гуанзэн, Ли Чжанфэн и Ли Дунгуан. Исследование явного развития туризма в культуре Чжоуи // Журнал Аньянгского педагогического колледжа. Второй выпуск-2015. -с 62-65. 田广增, 李占锋, 李东光. 周易文化的旅游显性化开发研究//安阳师范学院学报. 第二期. -2015. 62-65页.

3. Ю. Сюэцай. Определение понятия «туризм» в древнем Китае // Журнал профессионального института коммерции Уси Journal of Wuxi Vocational Institute of Commerce. Исследования по развитию туризма. Том 18-№4. - 2018. - с 33-38. 喻学才. 中国古代 “旅游” 的定义//无锡商业职业技术 学院学报 Journal of Wuxi Vocational Institute of Commerce. 旅游发展研究. 第 18 卷. -No4. - 2018. 33-38页.

4. Ю. Сюэцай. Определение понятия «туризм» в древнем Китае // Журнал профессионального института коммерции Уси. Исследования по развитию туризMa. Toм 18-№4. - 2018. - c 33-38. 喻学才. 中国古代 “旅游” 的定义//无锡商业职业技术学院学报 Journal of Wuxi Vocational Institute of Commerce. 旅游发展研究. 第 18 卷.-No4. - 2018.33-38页.

5. Чжан Линюнь. Обзор определений и концепций популярного туризма в мире - переосмысление природы туризма // Журнал туризма, том 23 № 1.-2008. -C. 80-01. 张凌云. 国际上流行的旅游定义和概念综述——兼对旅游本质的再认识// 旅游学刊, 第 23 卷 (第 1 期). 2008 第 86-01页

6. ЦЦао Шиту, южнокорейский Вэй из «Базового экзистенциализма и поэтической среды обитания» Хайдеггера, основанного на туристической сущности // Теоретический ежемесячник, 2012. №6, 156-158. 曹诗图, 韩国威从海德格尔的基础存在论与诗意栖居观解读旅游本质 // 理 论月刊，2012.第六期. 156-158.

7. ХанКоВэй. Оценка сущности и концепции туризма // Современный туризм Touri sm Тoday. Уханский университет науки и технологий. -2013.-с 46-48. 韩 国威. 旅游本质与概念评析//当代旅游Touri sm Today. 武汉科技大学.-2013. 46-48页.

8. Гао Кун, Ву Биху, Ли Мими. Переосмысление определения и коннотации туризма в сравнительной перспективе // Региональные исследования и разработки. Том 37. № 1. -Февраль 2018. -С. 86-91. 高璟, 吴必虎, 李咪咪. 比较视野下旅游定义及其内涵的再思考 // 地域研究 与开发. 第37卷. 第1期.-2018年2月.86-91页.

9. Цао Ши Ту Йо Гусинь, Дэн Су. Философский анализ природы туризма (2) // Наука туризма, № 1. - 2011. -с 80-87. 曹诗图漕国新, 邓苏。对旅游 本质的哲学辨析 II // 旅游科学, № 1.-2011.80-87页.

10. Гао Су Стандартизация условий туризма в Китае // Журнал туризма Tourism Journal 2007. -№ 8. -92-95 c. 高苏・我国旅游术语的规范化问题/ / 旅游学刊 2007.第8期. 92 - 95 页.

11. Чжан Байпин, Пэн Ин. Определение терминов туризма и их логическая взаимосвязь // ЖУРНАЛ УНИВЕРСИTETA AHШУH. JOURNAL OF ANSHUN UNIVERSITY. TOM 13. № 2. -Апрель 2011. -C. 73-76. 张白平, 彭瑛. 旅游学术语的定义及其逻辑关系//安顺学院学报 JOURNAL OF ANSHUN 
UNIVERSITY. 第 13 卷.No2. 2011 年 4 月.73-76页.

12. Ма Яофэн, Бай Кай. Дискуссия о сущности туризма на основе антропологии и теории систем // Наука о туризме. Том 21. № 3. -2001. -С. 27-31. 马耀峰, 白凯. 基于人学和系统论的旅游本质的探讨// 旅游科学. 21 卷.第三期. $-2001.27-31$ 页.

13. Се Яньцзюнь. Базовые исследования в области туризма (2-е издание) // Пекин; China Пресса о туризме в Китае. 2004, -c 41-84. Xie Yanjun. Tourism (the 2nd Edition) [M ] . Beijing: China Travel \& Tourism Press，2004.41-84. 谢彦君. 基础旅游学 (第 2 版)//北京; 中国旅游出版 社, 2004, 41-84页.

14. Цао Шиту, Чжэн Юфэй, Хуан Жун. Философский анализ концепций туризма // География и географическая информатика, -2006, № 4. -с 71-74. 曹 诗 图，郑宇飞，黄蓉。旅游概念的哲学辨析//地理与地理信息科学，-2006.第4期.71-74页.

15. У Биху. Что такое туризм? // Журнал туризма. Вып. 29. -№ 2. -2014. -с 121-124. 吴必虎. 旅游是什么?// 旅游学刊. 第 29 卷. 第 2期. 2014 年. 121-124页.

16. Су Айцзюнь. Говоря о связи между международным туризмом и внутренним туризмом - и обсуждая с товарищем Чжан Цзянем // Туристический форум. -1986. 22-24 с. 苏爱军. 也谈国际旅游和国内旅游的关系一兼与张践同志商榷// 旅游论坛. - 1986. 22-24页.

17. Чэнь Хайбо, Лю Син. Систематическое сравнение различий между командой острова международного туризма Хайнань и отдельными туристами // Журнал Наньянского педагогического университета. Journal of Nanyang Normal University. Том 11. № 6.2 июня 012. 61-64. 陈海波，刘星. 海南国际 旅游岛团队与散客旅游者差异的系统比较// 南阳师范学院学报Journal of Nanyang Normal University. 第11卷. No.6.2 012 年6 月. 61-64页.

18. Лю Хайлун, Чжан Ю. Культура туризма с точки зрения культурной антропологии // Исследования по управлению туризмом. Вторая половина марта 2017. -76 c. 刘海龙, 张玉. 以文化人类学视野论旅游文化 //旅游管理研究. 2017年3月下半月刊. -76页.

19. Тан Фенцюань. Обзор исследований в области спортивного туризма в стране и за рубежом. Li t erat ure Revi ew of Sport s Touri s m at Home and Abroad. // Вестник спортивной науки. -2016. - с 32-41. 谭分全. 国内外体育旅游研究评述 Li t erat ure Revi ew of Sport s Touri s m at Home and Abroad // 体育科技文献通报.-2016.32-41页.

20. Пэн Мингланг. Классификация туризма // Потребительская экономика. № 4. -1997. Стр. 12-15. 彭明朗 . 关于旅游的分类问题 / / 消费经 济. 第四期. -1997年. 12-15页.

21. Вейвэй Ху, Сянмин Чжэн. Исследование туристической классификации // Исследования по финансово-экономическим вопросам. Research on Financial andEconomic Issues. № 5. Maй 2012. -c 120-124. 胡卫伟，郑向敏.E 旅游者分类研究 // 财经问题研究 Research on Financial andEconomic Issues. №. 5.2012 年5 月. 120-124页.

22. Тянь Цзипэн, Чжу Цзиньлян, Вэй Цяньцянь, Цай Сяоян. Обзор и перспективы исследований в области делового туризма в стране и за рубежом в последние десять лет // Туристический форум. Вып.12. № 1.-2019. -с 86-97. 田纪鹏, 朱金梁, 魏倩倩, 蔡晓燕. 近十年国内外商务旅游 研究回顾与展望// 旅游论坛. 第12卷第1期.-2019年1月.86-97 页.

23. Чжан Вэйянь, Сюй Шумэй. Анализ развития медицинского туризма в Китае // Журнал института образования Цзямусы. № 3. -2009. 134, 135 с. 张维艳, 徐淑梅. 我国医疗保健旅游发展探析 // 佳木斯教育学院学报. No. 3. -2009.134, 135 页.

24. Йи Цзиронг. Комитет по развитию туризма района Хуандао, Циндао. Экономическая функция туризма и его роль в региональном развитии // Экономика и торговля Китая. -2017. - 46c. 伊纪荣. 青岛市黄岛区旅游发展委员会. 旅游业的经济功能及其在区域发展中的作用 // 中 国经贸.-2017. 46页.

25. Цай Яньшань. Эстетическая функция туризма // Литература и языкознание. Университет Шаогуань. Номер статьи: 1002- 2584. -2010. 67, 68 с. 蔡艳 山. 旅游的审美功能 // 文学与语言研究. 韶关学院. 文章编号: 1002-2584.-2010.67,68页.

26. Маринловский. 0 культуре [М.]. Фэй Сяотун и др // Пекин: Китайское издательство народной литературы и искусства, -1987. -14 с. 马林洛夫斯基. 文 化论 [M].费孝通等译. 北京: 中国民间文艺出版社，1987.14页.

27. Джеймс Ф. Петрик, Чжоу Суйвэнь. Преимущества отдыха и туризма // Туризм журнал. Vol.30. -№ 11, -2015. -с 1-4 . James F.Petrick, 邹穗雯. 休闲旅 游益处 //旅游学刊. Vol.30 No. 11,-2015. 1-4页.

28. Цао Шиту, Юнь Рулян, Лю Е. Философское мышление о концепции развития научного туризма [J]. Журнал Китайского университета Трех ущелий: гуманитарные и социальные науки. -№6. -2006. -с 84-87. 曹诗图，阚如良，刘晗. 对科学的旅游发展观的哲学思考[J].三峡大学学报： 人文社会科学版，2006(6): 84-87页.

29. Ли Сяньфэн. Обзор образовательных функций туризма // Пограничная экономика и культура. THE BORDER ECONOMY AND CULTURE. №12. -2008. -с 24-26. 李先峰. 旅游的教育功能研究综述// 边疆经济与文化 THE BORDER ECONOMY AND CULTURE. No12. -2008. 24-26页.

(c) ЛюИн (liuying_sw@mail.ru).

Журнал «Современная наука: актуальные проблемы теории и практики» 